\title{
Daytime descending intermediate layers observed over a sub-tropical Indian station Waltair during low-solar activity period
}

\author{
K. Niranjan ${ }^{1,3}$, B. Srivani ${ }^{2}$, and V. V. S. Naidu ${ }^{1}$ \\ ${ }^{1}$ Department of Physics, Andhra University, Visakhapantam 530 003, India \\ ${ }^{2}$ Department of Physics, GITAM University Hyderabad campus, Hyderabad, India \\ ${ }^{3}$ Graduate School of Environmental Studies, Nagoya University, Nagoya, Japan
}

Received: 29 October 2009 - Revised: 6 March 2010 - Accepted: 10 March 2010 - Published: 18 March 2010

\begin{abstract}
Study on daytime descending intermediate layer over subtropical Indian station Waltair $\left(17.7^{\circ} \mathrm{N}, 83.3^{\circ} \mathrm{E}\right.$ geographic, $6.4^{\circ} \mathrm{N}, 10^{\circ} \mathrm{E}$ geomagnetic, $20^{\circ} \mathrm{N}$ dip) located in the equatorial anomaly transition region, using an IPS 42 Digital Ionosonde during the low solar activity year 2004 showed that the layers occur in the altitude range of $140-160 \mathrm{~km}$ with maximum occurrence during winter solstice. The layers observed during daytime occur with a double peak variation throughout the year with less occurrence probability and shorter duration presence during forenoon hours. The morning layer descent was associated with a density increase where as during afternoon hours a decrease in density was observed. The downward drift velocity was about $8 \mathrm{~km} / \mathrm{h}$ during morning hours and between $7-11 \mathrm{~km} / \mathrm{h}$ during afternoon hours, with a low descent rate of around $4.5 \mathrm{~km} / \mathrm{h}$ during summer morning hours. The results indicate the presence of a $6 \mathrm{~h}$ tide at this location as observed from the characteristics of the descending layers, unlike at majority of locations where a significant semi diurnal trend is observed. The study brings out the complex nature of the tidal interaction at different locations.
\end{abstract}

Keywords. Ionosphere (Equatorial ionosphere)

\section{Introduction}

There has been considerable interest on the thin ionization layers called the Intermediate layers that form at the bottom side of the F-region ionosphere and descend over a period of several hours to lower altitudes through the valley region (Shen et al., 1976; Mathews, 1998). These layers are considered to be part of the sporadic E (Es) layer system because

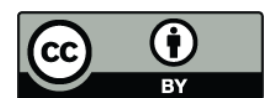

Correspondence to: K. Niranjan (niranjankandula@ hotmail.com) they appear to participate in a parenting like process for the generation of Es by steadily transporting metallic ions down to lower E-region heights (Fujitaka and Tohmatsu, 1973). The q-type Es observed in the height region of $105-110 \mathrm{~km}$ in the daytime equatorial ionograms is due to type II irregularities of the Equatorial electrojet region produced by the gradient drift instability mechanism where as the different type of Es layers such as $1, \mathrm{f}, \mathrm{c}$ and $\mathrm{h}$ type are known to be produced by wind/wind shear mechanism (Axford, 1963; Whitehead, 1961).

Dungey (1959) suggested that thin ionization layers can be produced by neutral wind shears and it is believed that these layers represent a local redistribution of ionization and are not the result of additional production (Axford, 1963; Osterman et al., 1994; Bishop and Earle, 2003), with corresponding plasma density depletions above and to a lesser extent, below (Smith, 1970; Osterman et al., 1994; Bishop et al., 2000). Experimental observations and theoretical simulations suggest that these layers are formed at altitudes where the ion vertical velocity has a convergent null and that neutral wind shears can drive ions against magnetic field to create such a situation.

Intermediate layers have been observed for over six decades by using different experimental techniques like ionosondes (e.g., McNicol and Gipps, 1951; Szuszczewicz et al., 1995), radars (Shen et al., 1976; Earle et al., 2000), sounding rockets (Smith, 1970; Bishop and Earle, 2003), and satellites (Miller et al., 1993; Heelis, 1999). Using Ionosonde data, Abdu et al. (1996), made a study on the long term trends in the sporadic E layer occurrences over Fortaleza, and found that the $\mathrm{h} / \mathrm{c}$ (high/cusp) type events occur during the sunlit hours with two maxima; one in the morning and other in the afternoon hours. The amplitudes of these maxima showed significant increase from 1975 to 1990 and also this diurnal double peak characteristic is similar to the Es local time distribution pattern over Cachoeria Paulista (Abdu

Published by Copernicus Publications on behalf of the European Geosciences Union. 

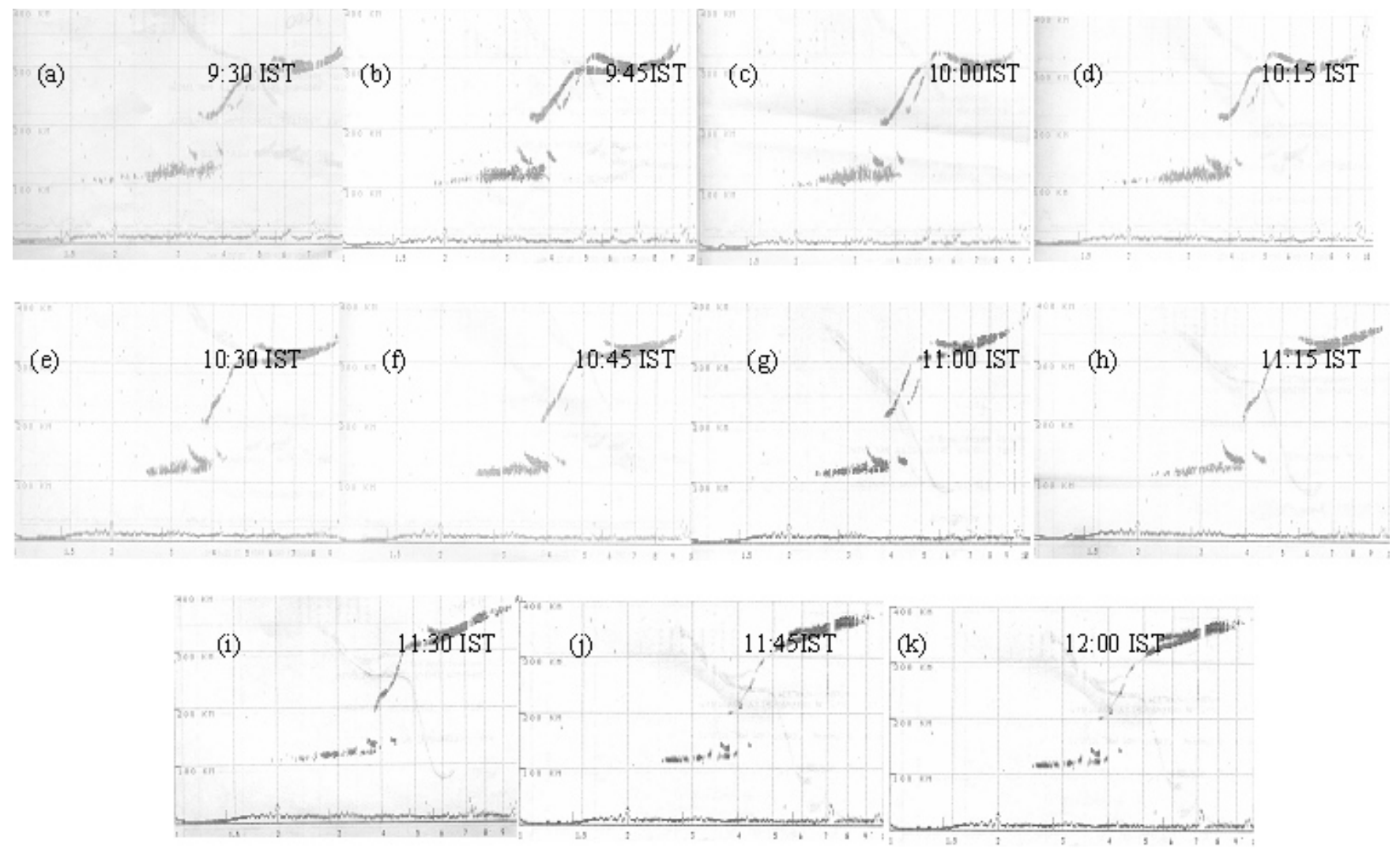

Fig. 1a. Sample Ionograms showing the daytime descending intermediate layers at Waltair during 09:30 to 12:00 IST on 30 January 2004.

and Batista, 1997). According to Wilkinson et al. (1992) and Szuszczewicz et al. (1995), these $\mathrm{h}$ and c types Es are attributed to the intermediate layers. These types of Es appear sometime individually or simultaneously (Wakai et al., 1987; Davies, 1990). Lee et al. (2003), also made investigations on this $\mathrm{h} / \mathrm{c}$ type Es and associated tidal motions in the Japanese sector. Rodger et al. (1981) provided good summary observations at different latitudes which indicate that the intermediate layer is a persistent feature of the night time ionosphere at Arecibo a sub-tropical station in the western sector.

However in the Indian sector not many reports are available on the occurrence and dynamical characteristics of the intermediate layers that provide evidence for the presence of various tidal signatures over the region. In this article we report the investigations carried out on the characteristics of the descending intermediate layers over a sub-tropical location Waltair $\left(17.7^{\circ} \mathrm{N}, 83.3^{\circ} \mathrm{E}\right)$ in India examining the ionosonde data for the low solar activity year of 2004. The station is located in the equatorial anomaly transition region. The observations indicate the presence of daytime layer in the altitude region between 160-180 km which descend downward resembling the sequential Es layer as classified by Mc Nicol and Gipps (1951). The results interestingly indicate the consistent presence of a $6 \mathrm{~h}$ periodicity in the occurrence of the descending intermediate layer during daytime. In contrast to the earlier reports, the experimental observations at this location show that the descent velocities are relatively higher and the layers show decrease in the ionization density during the afternoon layer descent.

\section{Data and observations}

We have examined the IPS-42 Digital ionosonde data over Waltair for the period 2004 to 2007, but considering the data continuity, we present here the data for the year 2004 only. A sequence of ionograms at $15 \mathrm{~min}$ interval, recorded at Waltair on 30 January 2004 with the presence of the intermediate layer is shown in Fig. 1a and b as a typical case. On this day, a weak descending Es layer was first observed at 09:30 IST at an altitude of about $140 \mathrm{~km}$, which gradually descended to an altitude of $128 \mathrm{~km}$ at around 12:00 IST and merged with the normal E layer. During the descent, the strength of the layer as indicated by foEs increased. At 12:45 h, a second descending layer was observed at around $162 \mathrm{~km}$ altitude, which descended and merged with the regular low type Es layer at around 15:30 IST.

Though there is a day-to-day variation in the time of appearance and disappearance, these descending layers were consistently observed with significant percent of occurrence. According to Wilkinson et al. (1992) and Szuszczewicz et 


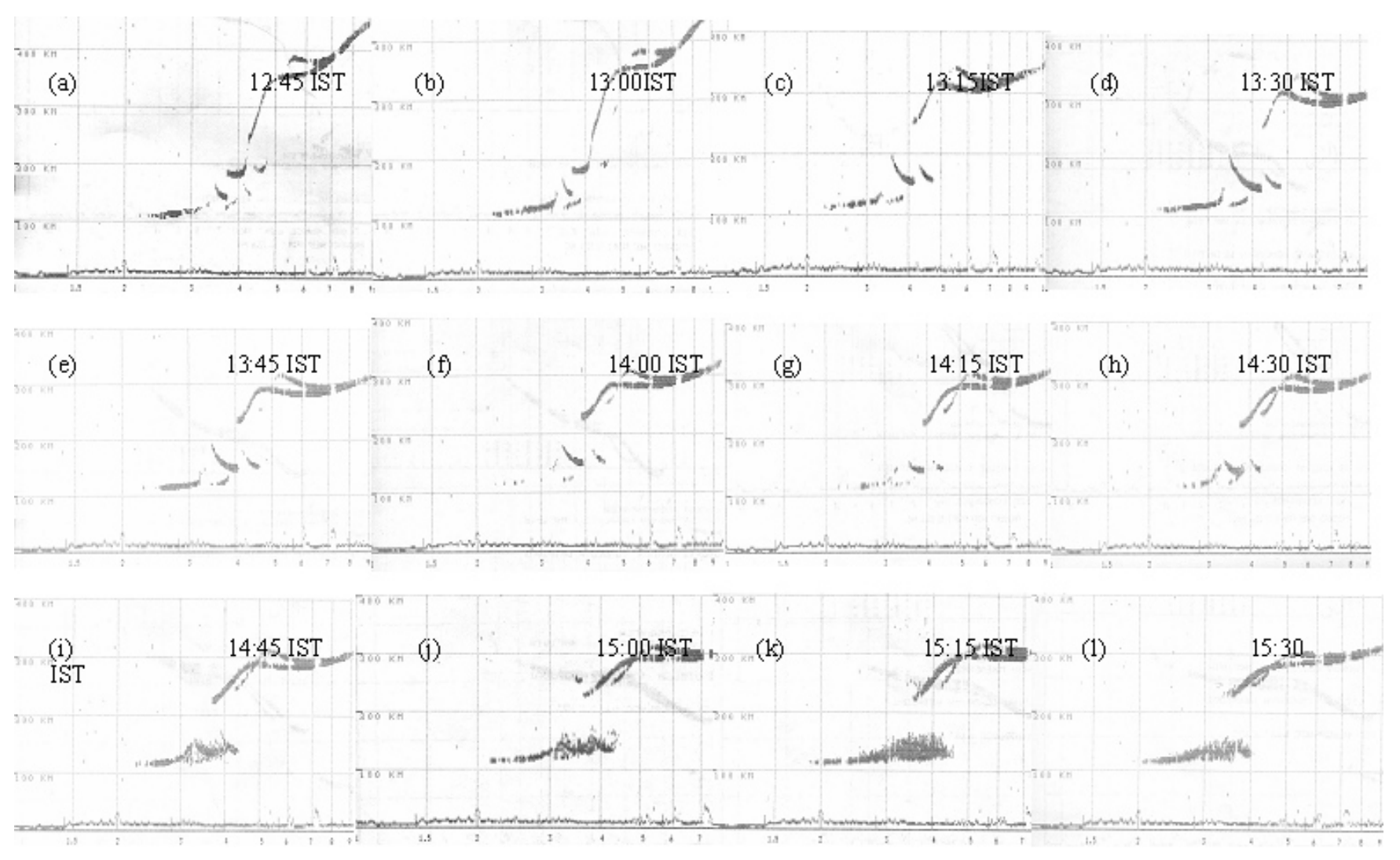

Fig. 1b. Sample Ionograms showing the daytime descending intermediate layers at Waltair during 12:45 to 15:30 IST on 30 January 2004.

al. (1995), the high (h) and cusp (c) type Es are attributed to the intermediate layers. Therefore we have considered only $\mathrm{h}$ and $\mathrm{c}$ type Es to study these descending layer properties.

Figure 2 shows the month to month variation of the percent occurrence of the intermediate layer. For evaluating the percent occurrence we have considered the days on which layer appears at least once in a day. It is clearly seen that the occurrence probability was more during winter solstice with a highest percentage of about $70 \%$ during months of December and January. The percentage of occurrence is low during summer solstice $(\sim 35 \%)$ and moderate during equinox $(\sim 45 \%)$. Interestingly, probability of occurrence of this intermediate layer is similar to that of the usually observed low and flat type Es at Waltair. The percentage occurrence of regular flat and low type Es is nearly $100 \%$ during winter solstice, when compared to the equinox and summer at this trans-equatorial station Waltair.

Rodger et al. (1981) and Lee et al. (2003) demonstrated similar seasonal variation with maximum occurrence during winter months at South Georgia $\left(54^{\circ} \mathrm{S}, 37^{\circ}\right)$ and in Japanese sector at latitude of $23^{\circ} \mathrm{N}$, respectively. In a tidal study, Amayenc (1974) found that the amplitude of the semi-diurnal tide in winter is about twice that in summer. Moreover, production and recombination do not dominate plasma distribution with height in the intermediate region in winter (as shown by Davies, 1990). Therefore, wind shear is primarily responsible for layer formation in winter, and layer formation is expected to be greater during this season (Lee et al., 2003). To see if the layer statistics show a similar semi diurnal variation in its occurrence, we have plotted in Fig. 3, the daytime variations in the occurrence probability of intermediate layers at Waltair during different seasons along with the virtual height of these descending layers (h'Es) during 2004. These layers showed a daytime double peak variation throughout the year with less percentage of occurrence during morning when compared to the afternoon. The occurrence probability of afternoon descending layer is about $35 \%$ during winter, $30 \%$ during equinox and $25 \%$ during summer where as the morning peak occurrence is below $15 \%$ during all the three seasons, though winter and equinox periods show a slightly higher probability in the forenoon hours. In contrast to the earlier results, the present results indicate the probable presence of a weak 6-hourly tide in the forenoon hours, but a relatively stronger presence in the afternoon hours. Strong blanketing Es precludes the observation of the descending layers during most of the nights and hence we are unable to present the characteristics of these layers during night time, though we expect to see a double peak appearance during night also as was reported for Arecibo by Rodger et al. (1981). During both the forenoon and afternoon hours the layer, when 


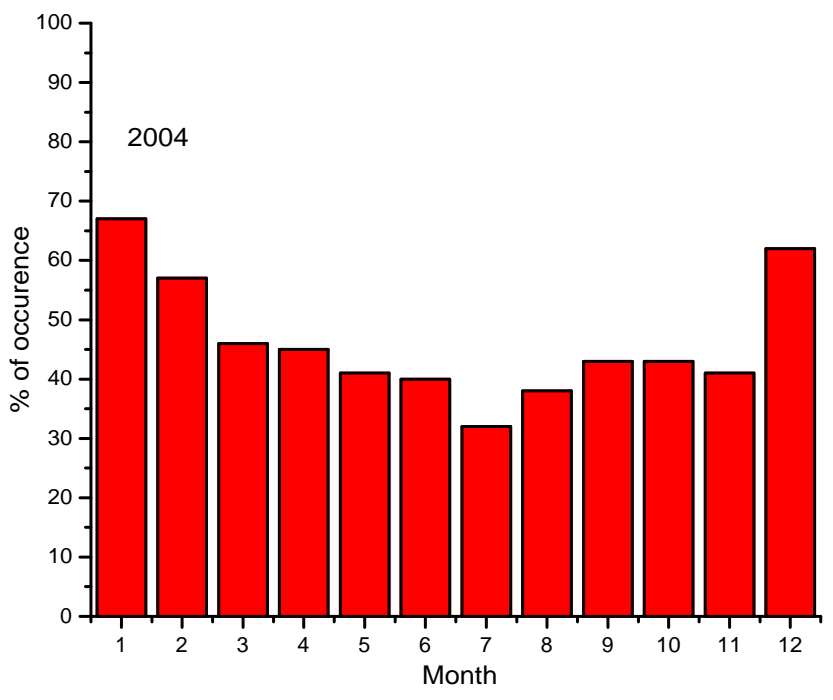

Fig. 2. Monthly mean percentage occurrence of descending intermediate layer for solar minimum period 2004 at Waltair.

observed, shows a steady descent in altitude. The descent velocities are relatively lower during forenoon hours compared to afternoon hours. Figure 3 also shows another periodicity of about $2 \mathrm{~h}$. For this periodicity, the ratio between the minimum value and the peak value is much larger than that of afternoon. For equinox, the ratio between the peak and the dip is about $0.5-0.8$ for forenoon, and 0.84 for afternoon. For summer it is 0.37 for forenoon and for afternoon it is 0.59 . However since the figure shows the mean behaviour during this months, the day to day features might have contributed to this variation. But by and large, there exist two layer groups, one in the forenoon between 06:0012:00 IST and the other between 13:00-18:00 IST. It may be noted that there is a clear break in the observation of the layer around local noon between 12:00 and 13:00 IST. This can not be considered as an artifact related to peak E-region ionization and subsequent masking of the layer observation since the peak density sustains for quite some time. Further, we also had many occasions when we observed the layer even during times of peak ionization density.

To bring out the month to month variation in the layer presence more clearly, the mean virtual height of the descending E layer and the normal E layer/Sporadic E (which we prefer to call as constant height layer though there is some variability in the height from time to time), are plotted as a function of IST in Fig. 4a (January to June 2004) and Fig. 4b (July to December 2004). The distinction between the constant height layer and the Intermediate layer was done during the scaling of ionograms. The ionograms of 15 -min intervals were checked for the presence of descending layer and if present, the virtual height of the layer was scaled simultaneously with the virtual height of the constant height $E$ layer or the normal Sporadic E layer. The data was consolidated for
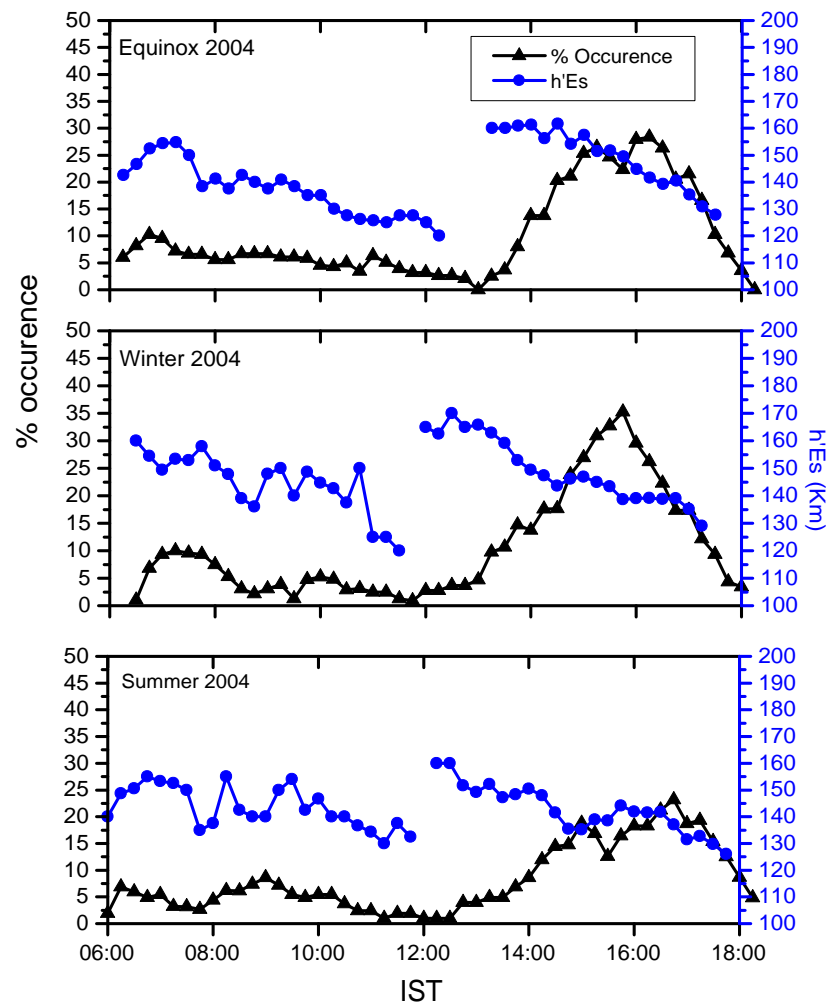

Fig. 3. Occurrence probability of the intermediate layers (black line) and their virtual heights, h'Es (blue line) during 2004 at Waltair.

each month and the mean virtual height for each 15-min time interval was evaluated along with the standard deviation. It may be seen that the intermediate layer did appear both during the forenoon and afternoon periods during all the months. The descending layer forms around the same altitude during March, July and December. In February and June the forenoon layer forms at an altitude slightly higher than the afternoon hours while in January, April, May, August, October, November, forenoon layer forms at a lower altitude. Since the plotted altitudes are the mean for each month, the increase in altitudes during the forenoon hours of some of the moths (for example February and July) should not be taken as ascent of the layer but only indicates that the altitudes at the time of first appearance change, with earlier onsets normally occurring at lower altitudes. It may be pointed out here that of the 11 days of observation of the layer in February, the layer appeared around 06:30 h only on two days at lower altitudes which is reflected in the figure. However, while comparing the descent rate, to ensure uniformity we have considered the same time duration for all the months i.e., between 08:30 to 12:00 noon for forenoon hours and 13:00 to $18: 30 \mathrm{~h}$ for afternoon hours, which indicate faster rate of descent of the afternoon layers during the equinox months and near equinox months of March, September and October, followed by winter months of January, February and December. 


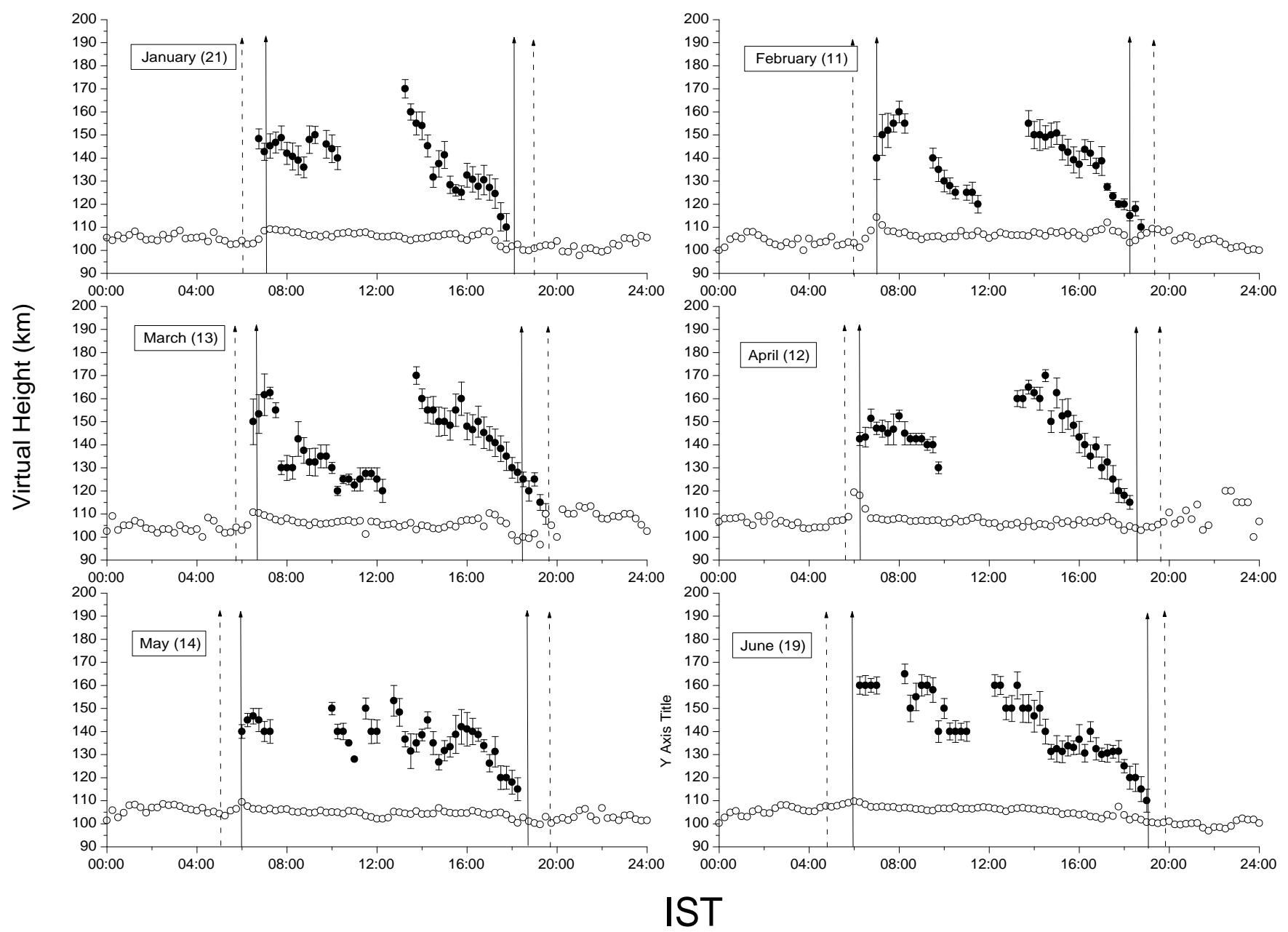

Fig. 4a. Monthly mean variation of the virtual height of descending intermediate layer (solid dots) Es along with constant height Es (open circles) for January to June 2004 at a sub-tropical station Waltair. The error bars indicate the standard deviation of the mean. The vertical solid lines indicate the sunrise and sunset times at ground level and the dashed lines indicate those at an altitude of $150 \mathrm{~km}$.

The rate of descent of the afternoon layers is almost the same during March, April and May. During May, the layer appearance and disappearance is highly variable and for very short durations, particularly in the forenoon hours.

To examine the strength of the layer during the descent, the average critical frequency of the descending layer during different seasons is plotted against IST in Fig. 5, along with the mean altitude of the descending layers. It is interesting to note that the morning layer descent was associated with density increase as was expected, but for the afternoon layers, the descent was associated with a decrease in the critical frequency which reflects a decrease in the layer density in all the seasons. Another point of interest is the velocity of layer decent which is seen to be faster initially for the forenoon events becomes slower before the layer merges with the normal E layer during the equinox. The layer descent velocity was more or less uniform during the afternoon hours but for a small retardation around the time it completes the descent and merges with the normal E layer. During winter and sum- mer months the velocity of descent during the forenoon hours was relatively low.

Figure 6 shows drift velocity of the intermediate layers on a typical winter day, 30 January 2004. On this day the layer in the forenoon hours appeared at an altitude of $140 \mathrm{~km}$ at $09: 15 \mathrm{~h}$ and descended to an altitude of $120 \mathrm{~km}$ around 11:30 IST . The initial velocity (with diffusion neglected) of the layer was around $20 \mathrm{~km} / \mathrm{h}$ and towards the end it was $6 \mathrm{~km} / \mathrm{h}$. The second layer appeared at an altitude of $160 \mathrm{~km}$ at 13:00 $\mathrm{h}$ and descended to an altitude of $122 \mathrm{~km}$ around $15: 15 \mathrm{~h}$. The velocity of descent during the first $15 \mathrm{~min}$ was quite high $(40 \mathrm{~km} / \mathrm{h})$ and it slowly came down to $8 \mathrm{~km} / \mathrm{h}$ before it merged with the normal E layer. This is a typical case which has shown high descent velocities. We have evaluated the mean descent velocities (diffusion neglected) during the forenoon and afternoon for the different seasons and compiled in Table 1 which indicate the lowest descent velocities in the forenoon hours of summer months and higher descent velocities during the afternoon hours of equinox. 

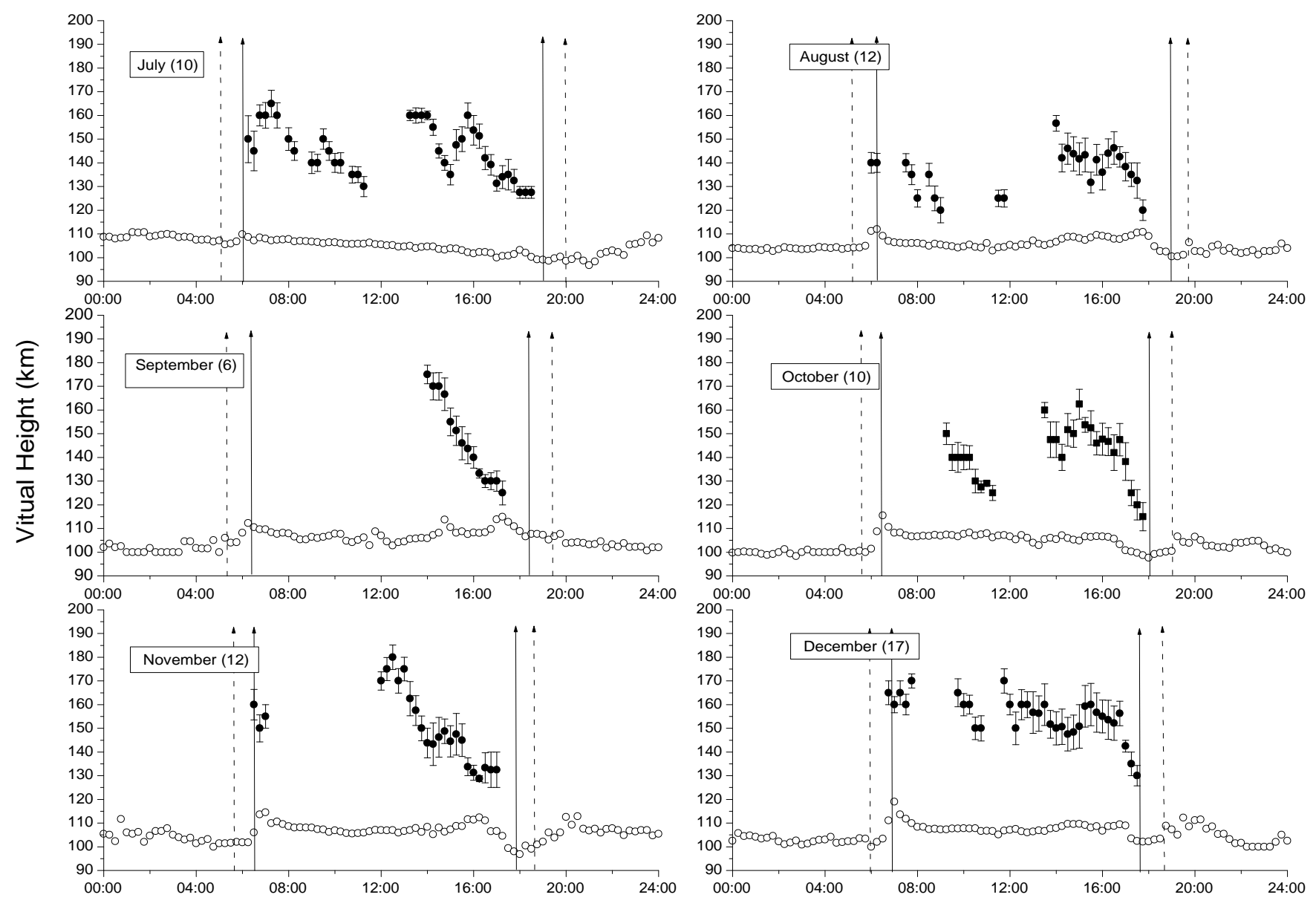

IST

Fig. 4b. Monthly mean variation of virtual height of descending intermediate layer (solid dots) Es along with constant height Es (open circles) for July to December 2004 at a sub-tropical station Waltair. The error bars indicate the standard deviation of the mean. The vertical solid lines indicate the sunrise and sunset times at ground level and the dashed lines indicate those at an altitude of $150 \mathrm{~km}$.

Table 1. Mean descent velocities of the intermediate layers.

\begin{tabular}{ccc}
\hline Season & $\begin{array}{c}\text { Forenoon descent } \\
\text { velocity }(\mathrm{km} / \mathrm{h})\end{array}$ & $\begin{array}{c}\text { Afternoon descent } \\
\text { velocity }(\mathrm{km} / \mathrm{h})\end{array}$ \\
\hline Winter & $8 \pm 0.96$ & $9 \pm 1.12$ \\
Equinox & $7 \pm 0.89$ & $11 \pm 1.78$ \\
Summer & $4.5 \pm 1.01$ & $7 \pm 1.34$ \\
\hline
\end{tabular}

\section{Discussion}

The observed features of the descending E layers at Waltair show a distinct difference from those reported so far with a consistent, $6 \mathrm{~h}$ periodicity in their occurrence thorough out the year. It is assumed that a convergent null is the only condition under which such layers will be formed and the general downward flow will only cause the accumu- lation of ions into a thick layer (Bristow and Watkins, 1991). According to Mathews and Bekeny (1979), the wind shear theory has been very successful in predicting the location of sporadic $\mathrm{E}$ and intermediate layers in the ionosphere $\mathrm{E}$ region. The layers form near regions of neutral wind shear when plasma is pushed down along a magnetic field line by a pole ward wind and upward from below by an equator ward wind, making the meriodional wind as the major player in the formation of the layers (Osterman et al., 1995). Using 15 days consecutive days of ionosonde observations at Townsville, Australia and with a comparison of NCAR TIGCM simulations, Wilkinson et al. (1992) reported that the layer processes occur at altitudes above $150 \mathrm{~km}$ and are identifiable with wind shear node convergence of ions, that the zonal wind control of the layers is insignificant and that the electric fields also play a decisive role in the effectiveness of ion convergence and downward transport processes at altitudes above $125 \mathrm{~km}$. The role of atmospheric tides is crucial in deciding the layer properties as they provide the 

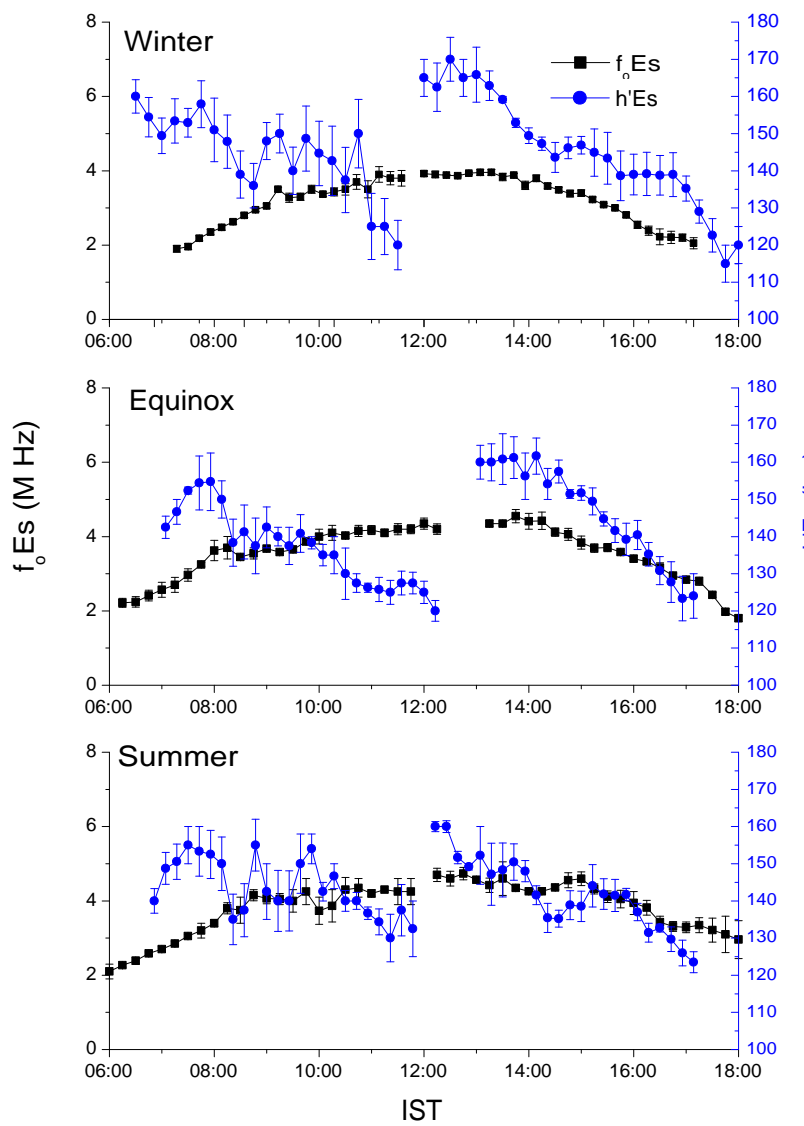

Fig. 5. Monthly mean seasonal variation of descending intermediate layer foEs \& h'Es during low solar activity year (2004) at Waltair.

downward propagating wind shears of ion convergent nodes that form and transport the layers to lower altitudes. Earlier studies (Fujitaka and Tohmatsu, 1973; Mathews and Bekeny, 1979; Tong et al., 1988; Morton et al., 1993) reported different tidal motions that occur in layer production. Using an ionosonde database of 12 stations from the Northern and Southern Hemispheres, Szuszczewicz et al. (1995) identified diurnal, semidiurnal and terdiurnal tidal modes as the causal mechanisms for layer formation and transport with primary controls driven by meridional and zonal wind shear forces. Lee et al. (2003) examined the seasonal characteristics of the tidal motions and found semidiurnal tides in January-March and November-December months and quarter diurnal tide (6 h) during other months. Haldoupis et al. (2006) interpreted the Height Time Intensity (HTI) records of these layers using the basic wind shear theory by taking into account the forcing effects of semi diurnal and diurnal tides in the lower thermosphere. Their study showed that the semi diurnal tide dominated over the diurnal tide in the upper E-region. In contrast to earlier studies, Lee et al. (2003) studied the seasonal characteristics of these layers and reported that the probability of occurrence of the layer with single peak shows that the semi-diurnal tide prevails in January to March and November

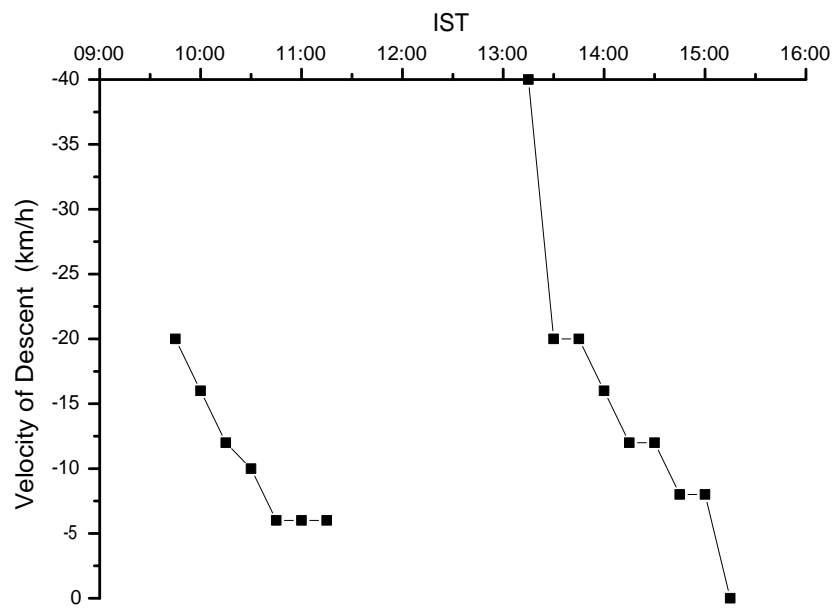

Fig. 6. Drift velocity of descending intermediate layer Es for a typical day of 30 January 2004 at Waltair.

to December while in the double peak months, although the occurrence is low, a quarter diurnal tide remains more dominant than the other tide periods. The present observations at Waltair also show the presence of a $6 \mathrm{~h}$ (quarter diurnal) tide over this sub-tropical location through out the year. As the layers descend their continued existence at high densities requires a steady accumulation of metallics. There is evidence however that lack of phase coherence between tidal modes at altitudes near $125 \mathrm{~km}$ can break up the layers and redistribute metallic ions (Wilkinson et al., 1992). Thus the day to day variability in occurrence of descending layers might be the result of variations in tides, electric fileds or metallic ion inventories.

The day to day variability in the descending layer observation might be due to the variations in tides, electric fields, metallic ion populations and also due to the influence of gravity waves (Nygren et al., 1990). However, considering the descent rates, most of the times, the descent rates were between $7-11 \mathrm{~km} / \mathrm{h}$ which are characteristic velocities of the semi diurnal tides of $S(2,4)$ mode (Williams, 1996) that propagate more freely in the lower thermosphere (Lee et al., 2003). This indicates that the observed layers could be due to complex mixture of the semi-diurnal and quarter diurnal tides. However, during summer forenoon hours, the descent velocities of $4.5 \mathrm{~km} / \mathrm{h}$ reflect the descent velocities of quarter diurnal tides $(2-4 \mathrm{~km} / \mathrm{h})$.

Regarding the plasma density of the layer, Osterman et al. (1994, 1995) and Carter and Forbes (1999) demonstrated that molecular and metallic ions dominate the compositions of the intermediate layers with molecular ions at high altitudes changing to metallic ions as they descend. The morning layer descent and associated density increase indicate that the descending convergent null could capture a large number of molecular and metallic ions (Osterman et al., 1994, 1995; Carter and Forbes, 1999; Earle et al., 2000) 
thereby contributing to the density enhancement. As reported by Lee et al. (2003), the phenomenon of layer descent and concurrent density decrease resemble the simulation result of Carter and Forbes (1999) that the diffusing zonal wind component in the afternoon would reduce the layer density. It is also possible that during noon hours, the sun is at the zenith resulting in the availability of more ionization for redistribution during noon hours resulting in ionization enhancement while in the evening, decrease in the ionization could partly contribute to the depletion in layer density.

At Arecibo, sub tropical latitude on the western sector, the tidal wind system is characterized by a diurnal tide in the altitude region of $80-100 \mathrm{~km}$ (Mathews, 1976; Harper, 1977), and a semidiurnal tide, which is dominant in the altitude above $100 \mathrm{~km}$ (Harper, 1977, 1981). Using height-time layer trajectories over Arecibo, Tong et al. (1988) showed a twice per day periodicity for the intermediate layers at upper heights which move fast down to $120 \mathrm{~km}$ with speeds ranging between 5 and $8 \mathrm{~km} / \mathrm{h}$, while at times the situation can be complicated by the additional action of a quarter diurnal tide in the upper E-region. Morton et al. (1993) and Mathews et al. (1993) confirmed the regular quarter diurnal periodicity of the layers during the Arecibo Initiative in Dynamics of the Atmosphere (AIDA) campaign. Mac Dougall (1974, 1978) studied the intermediate layers from ionograms and noted that the intermediate layers result primarily from wind shears connected with the motions of several tide modes and that their periodicities were related to semi-diurnal tidal oscillations. Morton et al. (1993) and Mathews et al. (1993) using the incoherent scatter Radar data during AIDA campaign confirmed regular quarter diurnal periodicity of descending layers and basing on their results postulated tidal influence as the cause of periodicity. Over Arecibo, the winds in the region below $110 \mathrm{~km}$ tend to be diurnal in nature while between $110 \mathrm{~km}$ to $180 \mathrm{~km}$ the neutral winds are dominated by semi diurnal tides (Harper, 1977, 1981). Gravity waves complicate the wind system either by constructively or destructively interfering with the tidal motions.

Descent rates of 3-4 km/h associated with the motion of the semi diurnal tides have been reported by many investigators (Fujitaka and Tohmatzu, 1973; Shen et al., 1976; Riggin et al., 1986; Nygen et al., 1990). However, Rowe (1974) reported that downward moving velocity of sporadic E layer associated with gravity wave can be as large as $12 \mathrm{~km} / \mathrm{h}$. Sporadic E layer is modulated not only by the tidal wave but also by salient gravity waves causing enormously large descent rate (Chu and Wang, 1997). Observations of Earle et al. (2000) reveal that multiple ionization, layers often appear and descend in rapid succession over Arecibo, suggesting that there is significant variation in the wind field over relatively shorter time scales, much shorter than semi diurnal, quarter diurnal and other lower order tidal modes, which suggests that gravity waves or local modulations of the large scale background winds may be more significant in the formation of the layers.
Thus the observed features of the daytime descending intermediate layers at Waltair a sub-tropical Indian station reveal that the layer occurs through out the year with a $6 \mathrm{~h}$ periodicity but with varying probability indicating the presence of a $6 \mathrm{~h}$ tidal mode over the location. The descent velocities which are higher than reported earlier indicate that the layer ionization is redistributed not only by the tidal wave but also by gravity waves causing large descent rates at times.

\section{Conclusions}

- Daytime descending intermediate layers that appear at the bottom of F-region is a frequent phenomenon at Waltair, a sub-tropical Indian station.

- The occurrence probability of these layers is highest in winter solstice, moderate during equinox and low during summer solstice.

- The layer occurrence showed a daytime double peak variation with two distinct layer groups, one in the forenoon (06:00-12:00 IST) and the other during afternoon (13:00-18:00 IST).

- The forenoon layer descent was associated with layer density increase indicating the strengthening of the layer while it decreased during the afternoon layer descent.

- The layer descent velocities were slightly higher than those reported earlier with mean afternoon descent velocities above $7 \mathrm{~km} / \mathrm{h}$ while the forenoon layer descent velocities were below $8 \mathrm{~km} / \mathrm{h}$ with lowest velocities during summer.

- The results indicate the presence of a 6-hourly tide over the location while the higher descent velocities could be due to the modulation of the layer ionization by gravity waves along with the tides.

Acknowledgements. The authors thank the reviewers for their comments and suggestions that helped in bringing the article into a better form. One of the authors (KN) thanks T. Shibata and the Graduate school of environmental studies, Nagoya University, Japan for the Visiting faculty position.

Topical Editor K. Kauristie thanks P. Wilkinson and another anonymous referee for their help in evaluating this paper.

\section{References}

Abdu, M. A. and Batista, I. S.: Sporadic E layer phenomena in the Brazilian geomagnetic anomaly: Evidence for a regular particles ionization source, J. Atmos. Terr. Phys., 39, 723-731, 1997.

Abdu, M. A., Batista, P., Muralikrishna, P., and Sobral, J. H. A.: Long term trends in sporadic E layers and electric fields over Fortaleza, Brazil, Geophys. Res. Lett., 23, 757-760, 1996. 
Amayenc, P.: Tidal oscillations of the meridional neutral wind at midlatitudes, Radio Sci., 9, 281-293, 1974.

Axford, W. I.: The formation and vertical movements of dense ionized layers in the ionosphere due to neutral wind shears, J. Geophys. Res., 68, 769-779, 1963.

Bishop, R. L., Earle, G. D., Herrero, F. A., and Bateman, T. T.: Observations of an intermediate layer during the Coqui II campaign, J. Geophys. Res., 105, 24963-24971, 2000.

Bishop, R. L. and Earle, G. D.: Metallic ion transport associated with midlatitude intermediate layer development, J. Geophys. Res., 108(A1), 1019, doi:10.1029/2002JA009411, 2003.

Bristow, W. A. and Watkins, B. J.: Numerical simulation of the formation of thin ionization layers at high latitudes, Phys. Res. Lett., 18(3), 404-407, 1991

Carter, L. N. and Forbes, J. M.: Global transport and localized layering of metallic ions in the upper atmospherer, Ann. Geophys., 17, 190-209, 1999, http://www.ann-geophys.net/17/190/1999/.

Chu, Y. and Wang, C.: Interferometry observations of three dimensional spatial structures of Sporadic E irregularities using the Chung-Li VHF Radar, Radio Sci., 32, 817-832, 1997.

Davies, K.: Ionospheric Radio, Peter Peregrinus Ltd., London, UK, 1990.

Dungey, J. W.: Effect of a magnetic field on turbulence in an ionized gas, J. Geophys. Res., 64(12), 2188-2191, 1959.

Earle, G. D., Bishop, R. L., Collins, S. C., Gonzalez, S. A., and Sulzer, M. P.: Descending layer variability over Arecibo, J. Geophys. Res., 105, 24951-24961, 2000.

Fujitaka, K. and Tohmatsu, T.: A tidal theory of the ionospheric intermediate layer, J. Atmos. Terr. Phys., 35, 425-438, 1973.

Harper, R. M.: Tidal winds in the 100- to $200-\mathrm{km}$ region at Arecibo, J. Geophys. Res., 82, 3243-3250, 1977.

Harper, R. M.: Some results on mean tidal structure and day-today variability over Arecibo, J. Atmos. Terr. Phys., 43, 255-261, 1981.

Heelis, R. A.: Ionization layers observed at middle latitudes by atmosphere Explorer-C, J. Atmos. Sol. Terr. Phys., 61, 407-414, 1999.

Haldoupis, C., Meek, C, Christakis, N, Pancheva, D., and Bourdillon, A.: Ionogram height-time-intensity observations of descending sporadic E layers at mid-latitude, J. Atmos. and Solar-Terr. Phys., 6, 539-557, 2006.

Lee, C.-C., Liu, J.-Y., Pan, C.-J., and Hsu, H.-H.: The intermediate layers and associated tidal motions observed by a digisonde in the equatorial anomaly region, Ann. Geophys., 21, 1039-1045, 2003,

http://www.ann-geophys.net/21/1039/2003/.

Mac Dougall, J. W.: $110 \mathrm{~km}$ neutral wind patterns, Planet Space Sci., 22, 545-558, 1974.

Mac Dougall, J. W.: Seasonal variation of semi diurnal winds in the dynamo region, Planet Space Sci., 26, 705-714, 1978.

Mathews, J. D., Morton, Y. T., and Zhou, Q.: Observations of ion layer motions during the AIDA campaign, J. Atmos. Solar-Terr. Phys., 55, 447-457, 1993.

Mathews, J. D.: Measurements of the diurnal tides in the 80-100 km altitude range at Arecibo, J. Geophys. Res., 81, 4671-4677, 1976.

Mathews, J. D.: Sporadic-E: current views and recent progress, J. Atmos. Solar-Terr. Phys., 60, 413-435, 1998.
Mathews, J. D. and Bekeny, F. S.: Upper atmosphere tides and the vertical motion of ionospheric sporadic layers at Arecibo, J. Geophys. Res., 84, 2743-2750, 1979.

McNicol, R. W. E. and Gipps, G. de V.: Characteristics of the E Region at Brisbane, J. Geophys. Res., 56(1), 17-31, 1951.

Miller, N. J., Grebowsky, J. M., Hedin, A. E., and Spencer, N. W.: Equatorial ion composition, 140-200 km, based on atmosphere Explorer E data, J. Geophys. Res., 98, 685-692, 1993.

Morton, Y. T., Mathews, J. D., and Zhou, Q.: Further evidence for a 6-h tide above Arecibo, J. Atmos. Solar-Terr. Phys., 55, 459-465, 1993.

Nygren, T., Lanchester, B. S., Huukskonen, A., Jalonen, L., Turunen, T., Rishbeth, H., and van Eyken, A. P.: Interference of tidal and gravity waves in the ionosphere and an associated sporadic-E layer, J. Atmos. Terr. Phys., 52, 609-615, 1990.

Osterman, G. B., Heelis, R. A., and Bailey, G. J.: Effects of zonal winds and metallic ions in the behavior of intermediate layers, J. Geophys. Res., 100, 7829-7838, 1995.

Osterman, G. B., Heelis, R. A., and Bailey, G. J.: Modeling the formation of intermediate layers at Arecibo latitudes, J. Geophys. Res., 99, 11357-11365, 1994.

Riggin, D., Swartz, W. E., Providakes, J., and Farley, D. T.: Radar studies of long wavelength waves associated mid latitude sporadic E layers, J. Geophys. Res., 91, 8011-8024, 1986.

Rodger, A. S., Fitzgerald, P. H., and Broom, S. M.: The nocturnal intermediate layer over South Georgia, J. Atmos. Terr. Phys., 43, 1043-1050, 1981.

Rowe, J. F.: Downward transport of nighttime Es layer into lower E region at Arecibo, J. Atmos. Terr Phys., 36, 225-231, 1974.

Shen, J. S., Schwartz, W. E., Farley, D. T., and Harper, R. M.: Ionization layers in the nighttime E region valley above Arecibo, J. Geophys. Res., 81(31), 5517-5526, 1976.

Smith, L. G.: A sequence of rocket observations of night-time Sporadic-E, J. Atmos. Terr. Phys., 32, 1247-1257, 1970.

Szuszczewicz, E. P., Roble, R. G., Wilkinson, P. J., and Hanbaba, R.: Coupling mechanisms in the lower ionospheric thermospheric system and manifestations in the formation and dynamics of intermediate and descending layers, J. Atmos. Solar-Terr. Phys., 57, 1483-1496, 1995.

Tong, Y., Mathews, J. D., and Ying, W. P.: An upper E-region quarterdiurnal tide at Arecibo, J. Geophys. Res., 93, 10047-10051, 1988.

Wakai, N., Ohyama, H., and Koizumi, T.: Manual of ionogram scaling, Radio Research Laboratory, Ministry of Posts and Telecommunications, Japan, 1987.

Whitehed, J. D.: The formation of the sporadic-E layer in the temperate zone, J. Atmos. Terr. Phys., 20, 49-58, 1961.

Wilkinson, P. J., Szuszczewicz, E. P., and Roble, R. G.: Measurements and modeling of intermediate, descending, and sporadic layers in the lower ionosphere: results and implications for global-scale ionospheric-thermospheric studies, Geophys. Res. Lett., 19, 95-98, 1992.

Williams, P. J. S.: Tides, atmospheric gravity waves and traveling disturbances in the ionosphere, in: Modern Radio Science, edited by: Kohl, H., Ruster, R., and Schlegel, K., European Geophysical Society, Germany, 139-180, 1996. 